\title{
A pilot study of basal ganglia and thalamus structure by high dimensional mapping in children with Tourette syndrome
} [version 1; peer review: 2 approved]

\author{
Alton C. Williams ${ }^{1}$, Marie E. McNeely2,3, Deanna J. Greene ${ }^{4-6}$, Jessica A. Church ${ }^{6,7}$, \\ Stacie L. Warren 4,8, Johanna M. Hartlein 4,6, Bradley L. Schlaggar5,6,9,10, \\ Kevin J. Black (1D-6,9, Lei Wang4,11,12 \\ ${ }^{1}$ Washington University School of Medicine, St. Louis, MO 63110, USA \\ ${ }^{2}$ Division of Biology and Biomedical Sciences, Washington University, St. Louis, MO 63110, USA \\ ${ }^{3}$ Current affiliation: Centene Corporation, St. Louis, MO 63105, USA \\ ${ }^{4}$ Department of Psychiatry, Washington University School of Medicine, St. Louis, MO 63110, USA \\ ${ }^{5}$ Department of Radiology, Washington University School of Medicine, St. Louis, MO 63110, USA \\ ${ }^{6}$ Department of Neurology, Washington University School of Medicine, St. Louis, MO 63110, USA \\ ${ }^{7}$ Current affiliation: Department of Psychology in The College of Liberal, University of Texas- Austin, Austin, TX 78712, USA \\ ${ }^{8}$ Current affiliation: Department of Mental Health, St. Louis VA Medical Center, St. Louis, MO 63110, USA \\ ${ }^{9}$ Department of Anatomy \& Neurobiology, Washington University School of Medicine, St. Louis, MO 63110, USA \\ ${ }^{10}$ Department of Pediatrics, Washington University School of Medicine, St. Louis, MO 63110, USA \\ ${ }^{11}$ Current affiliation: Department of Psychiatry and Behavioral Sciences, Northwestern University Feinberg School of Medicine \\ Chicago, Chicago, IL 60611, USA \\ ${ }^{12}$ Current affiliation: Department of Radiology, Northwestern University Feinberg School of Medicine Chicago, Chicago, IL 60611, \\ USA
}

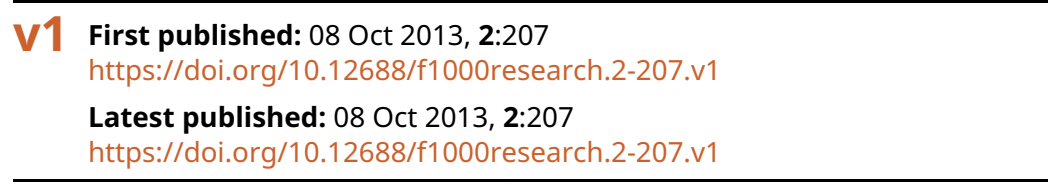

\section{Abstract}

Background: Prior brain imaging and autopsy studies have suggested that structural abnormalities of the basal ganglia (BG) nuclei may be present in Tourette Syndrome (TS). These studies have focused mainly on the volume differences of the BG structures and not their anatomical shapes. Shape differences of various brain structures have been demonstrated in other neuropsychiatric disorders using large-deformation, high dimensional brain mapping (HDBM-LD). A previous study of a small sample of adult TS patients demonstrated the validity of the method, but did not find significant differences compared to controls. Since TS usually begins in childhood and adult studies may show structure differences due to adaptations, we hypothesized that differences in BG and thalamus structure geometry and volume due to etiological changes in TS might be better characterized in children.

Objective: Pilot the HDBM-LD method in children and estimate effect sizes.

Methods: In this pilot study, T1-weighted MRIs were collected in 13

\section{Open Peer Review}

Approval Status

1 2

version 1

08 Oct 2013

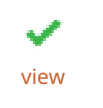

view

1. Jeremy S. Stern, St. George's Hospital and Medical School, London, UK

2. Kirsten R Müller-Vahı ID, Hannover Medical School, Hannover, Germany

Any reports and responses or comments on the article can be found at the end of the article. 
children with TS and 16 healthy, tic-free, control children. The groups were well matched for age. The primary outcome measures were the first 10 eigenvectors which are derived using HDBM-LD methods and represent the majority of the geometric shape of each structure, and the volumes of each structure adjusted for whole brain volume. We also compared hemispheric right/left asymmetry and estimated effect sizes for both volume and shape differences between groups.

Results: We found no statistically significant differences between the TS subjects and controls in volume, shape, or right/left asymmetry. Effect sizes were greater for shape analysis than for volume.

Conclusion: This study represents one of the first efforts to study the shape as opposed to the volume of the BG in TS, but power was limited by sample size. Shape analysis by the HDBM-LD method may prove more sensitive to group differences.

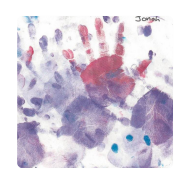

This article is included in the Rare diseases

collection.

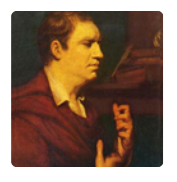

This article is included in the Tics collection.

Corresponding author: Kevin J. Black (kevin@wustl.edu)

Competing interests: No competing interests were disclosed.

Grant information: This study was funded by a research grant from the Tourette Syndrome Association to LW (Morphological abnormalities of the thalamus and basal ganglia in Tourette syndrome by computational anatomy). Manuscript preparation was supported in part by the National Institutes of Health grant K24 MH087913 to KJB.

The funders had no role in study design, data collection and analysis, decision to publish, or preparation of the manuscript.

Copyright: ( 2013 Williams AC et al. This is an open access article distributed under the terms of the Creative Commons Attribution License, which permits unrestricted use, distribution, and reproduction in any medium, provided the original work is properly cited. Data associated with the article are available under the terms of the Creative Commons Zero "No rights reserved" data waiver (CC0 1.0 Public domain dedication).

How to cite this article: Williams AC, McNeely ME, Greene DJ et al. A pilot study of basal ganglia and thalamus structure by high dimensional mapping in children with Tourette syndrome [version 1; peer review: 2 approved] F1000Research 2013, 2:207

https://doi.org/10.12688/f1000research.2-207.v1

First published: 08 Oct 2013, 2:207 https://doi.org/10.12688/f1000research.2-207.v1 


\section{Introduction}

Tourette syndrome (TS) is a chronic idiopathic syndrome characterized by the appearance of both vocal and motor tics during childhood or adolescence ${ }^{1,2}$. Tics are repetitive, stereotyped, suppressible movements or vocalizations that may include blinking, abdominal tensing, sniffing, or throat clearing ${ }^{3}$. TS affects approximately $0.5 \%$ of school-age children, but its causes and pathophysiology are not yet well understood ${ }^{4}$.

It has been suggested that problems with activity modulation in the basal ganglia and thalamus may contribute to the inability of TS patients to exercise behavioral inhibition ${ }^{5,6}$ as a result of these structures' effects on behavioral inhibition via the prefrontal, parietal, temporal, and cingulate cortices ${ }^{7}$. The basal ganglia and thalamus modulate cortical activity through cortico-basal ganglia-thalamo-cortical loops, composed of connections from the frontal cortex to the striatum, the striatum to the globus pallidus, substantia nigra, and thalamus, and the thalamus back to the cortex ${ }^{8}$.

Several lines of evidence support the presence of structural abnormalities in basal ganglia nuclei in individuals with $\mathrm{TS}^{4}$. Autopsy studies have found abnormalities within the basal ganglia, including increased number of neurons in the globus pallidus interna, decreased density and number of neurons in the globus pallidus pars externa, and decreased parvalbumin and choline acetyltransferase staining cholinergic interneurons in the caudate nucleus and putamen $^{9,10}$. However, since TS is rarely a fatal disease, the number of autopsied cases is limited ${ }^{11}$. Case studies of focal brain lesions have demonstrated new tic onset after lesions to the prefrontal cortex, thalamus, and basal ganglia ${ }^{12}$. In addition, encephalitis lethargica, frontal lobe degeneration, Huntington disease, Wilson disease, and other degenerative illnesses are associated with tics ${ }^{12}$. Further, some TS patients have benefitted from deep brain stimulation of the globus pallidus and thalamus in $\mathrm{TS}^{13-16}$. Collectively, these observations suggest a role for the basal ganglia, thalamus, and frontal cortex in tics.

Neuroimaging studies can be especially beneficial for studying structural abnormalities because they allow longitudinal study design, reduced investigator and sampling bias, and are relatively non-invasive. A number of MRI studies have examined anatomical volumes and cortical thickness in children and adults with TS and reported significant differences in various brain regions, including the caudate, sensorimotor and prefrontal cortex, and corpus callosum ${ }^{17}$. Most consistently, basal ganglia volumes were found to be smaller in TS subjects compared with healthy controls, but neuroanatomical shape differences and asymmetry abnormalities have not yet been consistently described ${ }^{18-24}$.

Large-deformation high dimensional brain mapping (HDBM-LD) is a computational anatomy tool that reduces the potential for human error in image analysis by further automating elements of image analysis. It has been successfully employed in characterizing shape and volume abnormalities of the hippocampus in neuropsychiatric disorders such as schizophrenia ${ }^{25-27}$, dementia of the Alzheimer type $^{28-31}$, depression ${ }^{32}$ and epilepsy ${ }^{33}$. It has also been applied to examine the thalamus in schizophrenia ${ }^{34}$.
HDBM-LD was applied to assess volume and shape differences in putamen, caudate nucleus, nucleus accumbens, globus pallidus, and thalamus in 15 adults with TS and 15 matched controls. No differences in volume or shape were found ${ }^{35}$. However, TS begins before adulthood. Several structural imaging studies in TS have found an interaction between regional brain volumes and age $\mathrm{e}^{21,22}$. It has been suggested that differences seen in adult studies may reflect adaptations or selection bias rather than changes etiologically relevant to $\mathrm{TS}^{20}$. Thus the present study applied HDBM-LD to investigate the volume and shape of these structures in children. We hypothesized that we would find reduced volume, abnormal shape, or abnormal right-to-left asymmetry in one or more of these structures, compared to age-matched controls. Given that there were no prior studies using the HDBM-LD method to analyze brain structures of children with TS in the literature, another goal of this pilot study was to estimate the effect size of these measures in this population.

\section{Materials and methods}

\section{Ethics statement}

A parent of each subject gave written informed consent to participate in the study, and each subject assented to participation. The study was approved by the Washington University Human Studies Committee (approval \# 03-1282).

\section{Participants}

This study included 13 children with TS (mean age $(\mathrm{SD})=12.44$ (2.22), 3 female, 12 right-handed) and 16 healthy controls (mean age $(\mathrm{SD})=12.39$ (1.92), 2 female, 15 right-handed). A movement disorders-trained physician examined all TS subjects and 10 of the control subjects. The remaining control subjects underwent neuropsychological evaluation as described previously ${ }^{36}$. Exclusion criteria were: inability to give informed consent, contraindication to MRI, currently symptomatic major depression, or lifetime history of mental retardation, autism, psychosis, mania, anorexia, bulimia, or drug abuse. All TS subjects met DSM-IV-TR criteria either for Tourette's Disorder or Chronic Tic Disorder. Disease duration and severity and other clinical characteristics are summarized in Table 1.

\section{Image acquisition and preprocessing}

A 1.5 T Siemens Vision system with a standard head receiver coil was used to collect T1-weighted MR structural images. Prior to scanning sessions, the transmitter was tuned and the main field was shimmed. Anatomic images used a 3D T1-weighted sequences (MPRAGE, 1x1x1.25 mm $\mathrm{m}^{3}$ voxels) ${ }^{37}$. Individual MPRAGE collections lasted approximately 6.5 minutes.

Initial image processing was done as described previously ${ }^{35,38}$. Using Analyze ${ }^{\mathrm{TM}}$ software (Rochester, Minnesota), images were linearly rescaled so that voxels with intensity two standard deviations above the mean in the corpus callosum were mapped to 255 , and voxels with intensity levels two standard deviations below the mean in the lateral ventricles were mapped to 0 .

Whole-brain volume for each subject, excluding the ventricles, was obtained from FreeSurfer (http://surfer.nmr.mgh.harvard.edu//) ${ }^{39}$. 
Table 1. Subject characteristics.

\begin{tabular}{|c|c|c|}
\hline & TS group & Control group \\
\hline$n$ & 13 & 16 \\
\hline Age at scan (mean \pm sd) & $12.44 \pm 2.22$ & $12.39 \pm 1.92$ \\
\hline Sex & $3 F / 10 M$ & $2 \mathrm{~F} / 14 \mathrm{M}$ \\
\hline Handedness & $12 \mathrm{R} / 1 \mathrm{~A}$ & $15 R / 1 L$ \\
\hline Years since onset of tics \pm sd & $4.31 \pm 2.69$ & NA \\
\hline YGTSS total tic score ${ }^{\star} \pm$ sd & $19.00 \pm 11.66$ & NA \\
\hline Number with ADHD diagnosis & 4 & 0 \\
\hline Number with OCD diagnosis & 5 & 0 \\
\hline \multicolumn{3}{|c|}{ Number who reported currently taking medication: } \\
\hline Atypical neuroleptics & 1 & 0 \\
\hline Typical neuroleptics & 1 & 0 \\
\hline Stimulants & 1 & 0 \\
\hline Benzodiazepines & 0 & 0 \\
\hline Selective serotonin reuptake inhibitors & 3 & 0 \\
\hline alpha-2 agonists & 5 & 0 \\
\hline Tricyclic antidepressants & 2 & 0 \\
\hline Tetracyclic antidepressants & 1 & 0 \\
\hline 1st generation antihistamines & 2 & 0 \\
\hline \multicolumn{3}{|c|}{ Number who reported past use of medication: } \\
\hline Atypical neuroleptics & 1 & 0 \\
\hline Typical neuroleptics & 1 & 0 \\
\hline Stimulants & 3 & 0 \\
\hline Benzodiazepines & 1 & 0 \\
\hline Selective serotonin reuptake inhibitors & 1 & 0 \\
\hline alpha-2 agonists & 5 & 0 \\
\hline Tricyclic antidepressants & 0 & 0 \\
\hline Tetracyclic antidepressants & 0 & 0 \\
\hline
\end{tabular}

\section{Large-Deformation High-Dimensional Brain Mapping (HDBM-LD)}

HDBM-LD was used to determine the volume and shape of the brain structures of interest in all subject scans, as described in detail elsewhere ${ }^{35}$. Briefly, on each subject's brain image, a single rater $(\mathrm{MEMcN})$ marked 27 points on the boundaries of the basal ganglia and thalamus in each hemisphere, which were used as an initial step to roughly align the brain image to a labeled standard brain image (template). From this starting point a differentiable, invertible transformation was computed that mapped all voxels of the subject's image to the template. Using this transformation, the labels on the template image are automatically assigned to the corresponding voxels of each subject's image. The authors checked the segmentation of each subject's MR image by visual inspection. This method is extremely reliable and has been validated against expert manual tracings ${ }^{35}$.

\section{Brain structure volume and shape analysis}

All brain structure volume and shape analysis methods were conducted as described previously ${ }^{35}$. We examined five structures: caudate nucleus, nucleus accumbens, globus pallidus, putamen, and thalamus. Volume for each structure was analyzed using a repeated measures ANCOVA, with diagnostic group as the between-subjects factor, brain hemisphere as the within-subjects factor, and age and whole brain volume as covariates. The degree of volumetric asymmetry was examined with the hemisphere effect, and group differences in volumetric asymmetry were assessed by examining the group-by-hemisphere interactions. We also analyzed the total (left and right hemisphere) structure volumes using an ANCOVA. The volume ANCOVAs were repeated with other covariates and factors, including estimated total intracranial volume, sex and handedness, none of which substantively changed the results.

Brain structure shapes were determined from the inter-subject deformation vector fields provided by the HDBM-LD transformations. Eigenvalues and a complete orthonormal set of eigenvectors representing shape variation were obtained using singular value decomposition (SVD) of the pooled covariance in the population studied. The coefficients (eigenscores) associated with the eigenvalues and eigenvectors were calculated for each subject and for each structure in each hemisphere ${ }^{35,40}$. We used the eigenscores based on the first ten eigenvectors for each structure in each hemisphere in a multivariate ANCOVA to test for group differences in 
shape. These first ten eigenscores explained $81-92 \%$ of the total variance for each structure.

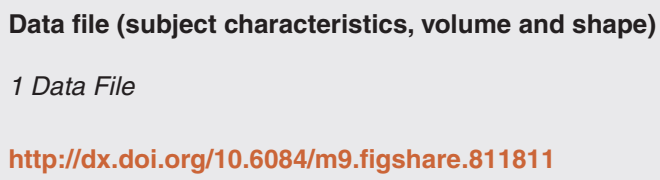

\section{Results}

Volume

Repeated-measures ANCOVAs showed no significant group effect for any structure. Structural volumes and ANCOVA statistics are shown in Table 2. Additionally, no significant hemisphere effects or group by hemisphere interactions were seen for any of the five structures examined (see Table 2).
Shape

MANCOVAs (using the first ten eigenscores as dependent variables) for each structure in each hemisphere showed no significant group effect (see Table 3). Effect sizes (Cohen's $f^{2}$ ) for both volume and shape are provided in Table 4; the effect sizes for the shape comparisons were larger than those for the volume comparisons.

\section{Discussion}

Using HDBM-LD, a validated method for automatic, highdimensional mapping of basal ganglia and thalamic structures, we found no significant differences in basal ganglia volumes or shape between children with TS and matched control children. For most basal ganglia regions, this reflects the conclusions of a recent review ${ }^{17}$. For instance, two groups found increased putamen volume in $\mathrm{TS}^{41,42}$, but a larger study found decreased volume ${ }^{43}$. However, the majority of these studies found no abnormality in putamen, similar to the current study. Three other studies, including the HDBM-LD

Table 2. Volumes of the structures of interest $\left(\mathrm{mm}^{3}\right)$.

\begin{tabular}{|c|c|c|c|c|c|c|c|c|}
\hline & & \multicolumn{2}{|l|}{ TS $(n=13)$} & \multicolumn{2}{|c|}{ Control $(n=16)$} & \multicolumn{3}{|c|}{$\begin{array}{l}\text { ANCOVA statistics } \\
\text { (hemisphere by } \mathrm{dx} \text { ) }\end{array}$} \\
\hline & & Mean (std) & {$\left[95 \%\right.$ Cls] $\mathrm{mm}^{3}$} & Mean (std) & {$\left[95 \%\right.$ Cls] $\mathrm{mm}^{3}$} & $\mathbf{F}$ & $d f$ & $\mathbf{P}$ \\
\hline Caudate & $\begin{array}{l}L \\
R \\
T\end{array}$ & $\begin{array}{l}3736(271) \\
3712(545) \\
7448(731)\end{array}$ & $\begin{array}{l}{[3581,3890]} \\
{[3401,4023]} \\
{[7030,7865]}\end{array}$ & $\begin{array}{l}3667(270) \\
3678(543) \\
7345(729)\end{array}$ & $\begin{array}{l}{[3528,3806]} \\
{[3398,3957]} \\
{[6969,7720]}\end{array}$ & 0.040 & 1,25 & 0.84 \\
\hline $\begin{array}{l}\text { Nucleus } \\
\text { accumbens }\end{array}$ & $\begin{array}{l}L \\
R \\
T\end{array}$ & $\begin{array}{l}460(46) \\
455(50) \\
915(74)\end{array}$ & $\begin{array}{l}{[434,487]} \\
{[426,483]} \\
{[873,957]}\end{array}$ & $\begin{array}{l}462(46) \\
456(50) \\
918(73)\end{array}$ & $\begin{array}{l}{[438,485]} \\
{[430,481]} \\
{[880,955]}\end{array}$ & 0.000 & 1,25 & 0.996 \\
\hline Globus pallidus & $\begin{array}{l}\mathrm{L} \\
\mathrm{R} \\
\mathrm{T}\end{array}$ & $\begin{array}{l}1826(126) \\
1859(145) \\
3685(248)\end{array}$ & $\begin{array}{l}{[1754,1898]} \\
{[1776,1942]} \\
{[3544,3827]}\end{array}$ & $\begin{array}{l}1804(125) \\
1800(144) \\
3603(247)\end{array}$ & $\begin{array}{l}{[1739,1868]} \\
{[1726,1874]} \\
{[3476,3730]}\end{array}$ & 0.768 & 1,25 & 0.39 \\
\hline Putamen & $\begin{array}{l}L \\
R \\
T\end{array}$ & $\begin{array}{l}5925(367) \\
5822(401) \\
11748(724)\end{array}$ & $\begin{array}{l}{[5716,6135]} \\
{[5593,6052]} \\
{[11334,12161]}\end{array}$ & $\begin{array}{l}5705(365) \\
5671(399) \\
11376(721)\end{array}$ & $\begin{array}{l}{[5517,5893]} \\
{[5465,5877]} \\
{[11005,11748]}\end{array}$ & 0.487 & 1,25 & 0.49 \\
\hline Thalamus & $\begin{array}{l}L \\
R \\
T\end{array}$ & $\begin{array}{l}8076(557) \\
8143(480) \\
16219(805)\end{array}$ & $\begin{array}{l}{[7757,8394]} \\
{[7869,8418]} \\
{[15759,16679]}\end{array}$ & $\begin{array}{l}7931(555) \\
7888(478) \\
15819(802)\end{array}$ & $\begin{array}{l}{[7645,8217]} \\
{[7642,8134]} \\
{[15406,16232]}\end{array}$ & 0.196 & 1,25 & 0.66 \\
\hline
\end{tabular}

$\mathrm{L}=$ left, $\mathrm{R}=$ right, $\mathrm{T}$ = total volume. Repeated-measures ANOVA of each structure showed no significant group effect. Further, we found no hemisphere effect or group by hemisphere interactions for any of the structures (age and whole brain volume w/out ventricles as covariates).

Table 3. Shape comparison of the thalamus and basal ganglia structures (TS vs. control).

\begin{tabular}{|c|c|c|c|c|}
\hline \multirow[b]{2}{*}{ Structure } & & \multicolumn{2}{|c|}{$\begin{array}{l}\text { MANCOVA } \\
\text { statistics }\end{array}$} & \multirow[b]{2}{*}{$\mathbf{P}$} \\
\hline & & $\mathbf{F}$ & $d f$ & \\
\hline Nucleus accumbens & $\begin{array}{l}\mathrm{L} \\
\mathrm{R}\end{array}$ & $\begin{array}{l}1.63 \\
1.91\end{array}$ & $\begin{array}{l}10,17 \\
10,17\end{array}$ & $\begin{array}{l}0.18 \\
0.11\end{array}$ \\
\hline Caudate & $\begin{array}{l}\mathrm{L} \\
\mathrm{R}\end{array}$ & $\begin{array}{l}1.31 \\
.739\end{array}$ & $\begin{array}{l}10,17 \\
10,17\end{array}$ & $\begin{array}{l}0.30 \\
0.68\end{array}$ \\
\hline Globus pallidus & $\begin{array}{l}\mathrm{L} \\
\mathrm{R}\end{array}$ & $\begin{array}{l}.231 \\
.848\end{array}$ & $\begin{array}{l}10,17 \\
10,17\end{array}$ & $\begin{array}{l}0.99 \\
0.59\end{array}$ \\
\hline Putamen & $\begin{array}{l}\mathrm{L} \\
\mathrm{R}\end{array}$ & $\begin{array}{l}.285 \\
.740\end{array}$ & $\begin{array}{l}10,17 \\
10,17\end{array}$ & $\begin{array}{l}0.98 \\
0.68\end{array}$ \\
\hline Thalamus & $\begin{array}{l}\mathrm{L} \\
\mathrm{R}\end{array}$ & $\begin{array}{l}.705 \\
.893\end{array}$ & $\begin{array}{l}10,17 \\
10,17\end{array}$ & $\begin{array}{l}0.71 \\
0.56\end{array}$ \\
\hline
\end{tabular}

$\mathrm{L}=$ left, $\mathrm{R}=$ right, $\mathrm{T}=$ total volume. Multivariate analysis of the first 10 eigenvectors of each structure showed no significant group effect (age as covariate). 


\section{Table 4. Effect sizes.}

\begin{tabular}{lll} 
& \multicolumn{1}{c}{ Partial $\boldsymbol{\eta}$} & Cohen's $\mathbf{f}^{\mathbf{2}}$ \\
\hline Volumes (total structure volumes) & \\
\hline Caudate & $5.51 \times 10^{-3}$ & $5.54 \times 10^{-3}$ \\
\hline Nucleus accumbens & $2.77 \times 10^{-4}$ & $2.78 \times 10^{-4}$ \\
\hline Globus pallidus & $2.94 \times 10^{-2}$ & $3.03 \times 10^{-2}$ \\
\hline Putamen & $6.79 \times 10^{-2}$ & $7.29 \times 10^{-2}$ \\
\hline Thalamus & $6.42 \times 10^{-2}$ & $6.86 \times 10^{-2}$ \\
\hline Volumes (hemisphere ${ }^{*} \mathrm{dx}$ effects) & \\
\hline Caudate & $2.00 \times 10^{-3}$ & $2.00 \times 10^{-3}$ \\
\hline Nucleus accumbens & $1.22 \times 10^{-6}$ & $1.22 \times 10^{-6}$ \\
\hline Globus pallidus & $3.00 \times 10^{-2}$ & $3.09 \times 10^{-2}$ \\
\hline Putamen & $1.90 \times 10^{-2}$ & $1.94 \times 10^{-2}$ \\
\hline Thalamus & $8.00 \times 10^{-3}$ & $8.06 \times 10^{-3}$ \\
\hline Shapes (principal components): & \\
\hline Left & & \\
\hline Caudate & 0.436 & 0.773 \\
\hline Nucleus accumbens & 0.490 & 0.961 \\
\hline Globus pallidus & 0.120 & 0.136 \\
\hline Putamen & 0.144 & 0.168 \\
\hline Thalamus & 0.293 & 0.414 \\
\hline Right & 0.303 & 0.435 \\
\hline Caudate & 0.303 & 0.435 \\
\hline Nucleus accumbens & 0.530 & 1.128 \\
\hline Globus pallidus & 0.333 & 0.499 \\
\hline Putamen & 0.524 \\
\hline Thalamus & & \\
\hline & & \\
\hline
\end{tabular}

study in adults with TS, found no volumetric change in any basal ganglia structure ${ }^{35,44-46}$. Possibly there is no true difference in these structures in TS when groups are matched carefully for age, sex and handedness. Alternatively, structural abnormalities in TS may be limited to certain subgroups, such as those with more severe tics or with ADHD.

On the other hand, the largest published MRI study of basal ganglia volume compared 154 adults and children with TS to 130 ticfree control subjects, and found that the caudate was $4.9 \%$ smaller in the TS group $(\mathrm{p}<0.01)^{43}$. Two other groups also found lower caudate volume in samples of 18-23 TS subjects and a similar number of controls $23,24,47,48$. The possible etiologic relevance of this finding is highlighted by the observation that a smaller caudate nucleus in adolescents with TS predicts more severe symptoms in early adulthood $^{49}$. The largest of the studies that did not find significant decreases in caudate volume was that of Roessner et al. ${ }^{42}$, which compared 55 subjects with TS to 42 control subjects. The other studies with negative findings regarding caudate volume, including the present one, had fewer than 20 TS subjects each. It is possible these negative results represent a Type II error.

The present study and the HDBM-LD study in adults represent some of the first efforts to study the shape (as opposed to the volume) of basal ganglia nuclei in TS, and provide effect size estimates for planning a study with larger samples.

\section{Author contributions}

LW and KJB designed the study. JAC, BLS, JMH and KJB collected the data. MEMcN, ACW, DJG, SLW and LW analyzed the data. $\mathrm{MEMcN}, \mathrm{ACW}$ and KJB wrote the first draft of the manuscript. All authors were involved in revising the manuscript and agreed to the final content.

\section{Competing interests}

No competing interests were disclosed.

\section{Grant information}

This study was funded by a research grant from the Tourette Syndrome Association to LW (Morphological abnormalities of the thalamus and basal ganglia in Tourette syndrome by computational anatomy). Manuscript preparation was supported in part by the National Institutes of Health grant K24 MH087913 to KJB.

The funders had no role in study design, data collection and analysis, decision to publish, or preparation of the manuscript.

\section{Acknowledgments}

We thank Mary Creech, RN, MSW, Emily Bihun, M.Ed. Counseling, Audrey Lim, and Jonathan M Koller BSEE BSBME for assistance with subject recruitment, data management and analysis.
1. American Psychiatric Association, Diagnostic and Statistical Manual of Mental Disorders, Fourth Edition, Text Revision., Washington, DC American Psychiatric Association. 2000; 943. Reference Source

2. Definitions and classification of tic disorders. The Tourette Syndrome Classification Study Group. Arch Neurol. 1993; 50(10): 1013-1016. PubMed Abstract | Publisher Full Text

3. Black KJ: Tics,. in Encyclopedia of Movement Disorders,. K. Kompoliti, et al., Editors., Elsevier (Academic Press): Oxford. 2010; p. 231-236.

4. Black KJ: Tourette syndrome and other tic disorders. eMedicine. 2009. Reference Source

5. Mink JW: Basal ganglia dysfunction in Tourette's syndrome: a new hypothesis.
Pediatr Neurol. 2001; 25(3): 190-8.

PubMed Abstract | Publisher Full Text

6. Peterson BS, Skudlarski P, Anderson AW, et al: : A functional magnetic resonance imaging study of tic suppression in Tourette syndrome. Arch Gen Psychiatry. 1998; 55(4): 326-33. PubMed Abstract | Publisher Full Text

7. Goldman-Rakic P: Circuitry of primate prefrontal cortex and regulation of behavior by representation memory. in Handbook of Physiology: the Nervous System. V. Mountcastle, F. Plum, and S. Geiger, Editors., American Physiological Socity: Bethesda, MD.1987; p. 254-373. Publisher Full Text

8. Haber SN: Neuroanatomy of reward: A view from the ventral striatum. in Neurobiology of Sensation and Reward,. J.A. Gottfried, Editor., CRC Press: Boca 
Raton, FL. 2011; 235-262.

PubMed Abstract

9. Kalanithi PS, Zheng W, Kataoka Y, et al: Altered parvalbumin-positive neuron distribution in basal ganglia of individuals with Tourette syndrome. Proc Natl Acad Sci U S A. 2005; 102(37): 13307-13312.

PubMed Abstract | Publisher Full Text | Free Full Text

10. Kataoka Y, Kalanithi PS, Grantz H, et al.: Decreased number of parvalbumin and cholinergic interneurons in the striatum of individuals with Tourette syndrome. $J$ Comp Neurol. 2010; 518(3): 277-91.

PubMed Abstract | Publisher Full Text | Free Full Text

11. Swerdlow NR, Young AB: Neuropathology in Tourette syndrome: an update. Adv Neurol. 2001; 85: 151-161.

PubMed Abstract

12. Kurlan R: The differential diagnosis of tic disorders., in Tourette Syndrome,. D. Martino and J.F. Leckman, Editors., Oxford University Press: New York. 2013; 395-401.

13. Cannon E, Silburn $P$, Coyne $T$, et al:: Deep brain stimulation of anteromedial globus pallidus interna for severe Tourette's syndrome. Am J Psychiatry. 2012; 169(8): 860-6.

PubMed Abstract | Publisher Full Text

14. Servello D, Porta M, Sassi M, et al:: Deep brain stimulation in 18 patients with severe Gilles de la Tourette syndrome refractory to treatment: the surgery and stimulation. J Neurol Neurosurg Psychiatry. 2008; 79(2): 136-142. PubMed Abstract

15. Muller-Vahl KR, et al:: European clinical guidelines for Tourette syndrome and other tic disorders. Part IV: deep brain stimulation. Eur Child Adolesc Psychiatry. 2011; 20(4): 209-17.

PubMed Abstract | Publisher Full Text

16. Ackermans L, Duits A, van der Linden C, et al:: Double-blind clinical trial of thalamic stimulation in patients with Tourette syndrome. Brain. 2011; 134(Pt 3): 832-44.

PubMed Abstract | Publisher Full Text

17. Greene DJ, Black KJ, Schlaggar BL: Neurobiology and functional anatomy of tic disorders,. in Tourette Syndrome,. D. Martino and J.F. Leckman, Editors., Oxford University Press: Oxford. 2013

18. Berthier ML, Bayes A, Tolosa ES: Magnetic resonance imaging in patients with concurrent Tourette's disorder and Asperger's syndrome. J Am Acad Child Adolesc Psychiatry. 1993; 32(3): 633-9. PubMed Abstract | Publisher Full Text

19. Castellanos FX, Giedd JN, Hamburger SD, et al:: Brain morphometry in Tourette's syndrome: the influence of comorbid attention-deficit/hyperactivity disorder. Neurology. 1996; 47(6): 1581-1583.

PubMed Abstract | Publisher Full Text

20. Gerard E, Peterson BS: Developmental processes and brain imaging studies in Tourette syndrome. J Psychosom Res. 2003; 55(1): 13-22. PubMed Abstract | Publisher Full Text

21. Peterson BS, Staib L, Scahill L, et al.: Regional brain and ventricular volumes in Tourette syndrome. Arch Gen Psychiatry. 2001; 58(5): 427-40. PubMed Abstract | Publisher Full Text

22. Peterson $B S$, Thomas $P$, Kane MJ, et al.: Basal Ganglia volumes in patients with Gilles de la Tourette syndrome. Arch Gen Psychiatry. 2003; 60(4): 415-24. PubMed Abstract | Publisher Full Text

23. Makki, MI, Behen M, Bhatt A, et al:: Microstructural abnormalities of striatum and thalamus in children with Tourette syndrome. Mov Disord. 2008; 23(16): 2349-56.

PubMed Abstract | Publisher Full Text

24. Müller-Vahl KR, Kaufmann J, Grosskreutz J, et al: Prefrontal and anterior cingulate cortex abnormalities in Tourette Syndrome: Evidence from voxelbased morphometry and magnetization transfer imaging. BMC Neurosci. 2009; 10: 47 .

PubMed Abstract | Publisher Full Text | Free Full Text

25. Csernansky JG, Wang L, Jones D, et al.: Hippocampal deformities in schizophrenia characterized by high dimensional brain mapping. Am J Psychiatry. 2002; 159(12): 2000-6. PubMed Abstract | Publisher Full Text

26. Wang L, Joshi SC, Miller Ml, et al:: Statistical analysis of hippocampal asymmetry in schizophrenia. Neuroimage. 2001; 14(3): 531-45. PubMed Abstract | Publisher Full Text

27. Smith MJ, Wang L, Cronenwett W, et al:: Thalamic morphology in schizophrenia and schizoaffective disorder. J Psychiatr Res. 2011; 45(3): 378-85. PubMed Abstract | Publisher Full Text

28. Wang L, Harms MP, Staggs JM, et al.: Donepezil treatment and changes in hippocampal structure in very mild Alzheimer disease. Arch Neurol. 2010; 67(1): 99-106.

PubMed Abstract | Publisher Full Text | Free Full Text

29. Csernansky JG, Wang L, Joshi S, et al.: Early DAT is distinguished from aging by high-dimensional mapping of the hippocampus. Dementia of the Alzheime type. Neurology. 2000; 55(11): 1636-43. PubMed Abstract | Publisher Full Text
30. Wang L, Swank JS, Glick IE, et al:: Changes in hippocampal volume and shape across time distinguish dementia of the Alzheimer type from healthy aging. Neuroimage. 2003; 20(2): 667-82.

PubMed Abstract | Publisher Full Text

31. Mamah D, Harms MP, Wang L, et al.: Basal ganglia shape abnormalities in the unaffected siblings of schizophrenia patients. Biol Psychiatry. 2008; 64(2): $111-20$.

PubMed Abstract | Publisher Full Text | Free Full Text

32. Posener JA, Wang L, Price JL, et al.: High-dimensional mapping of the hippocampus in depression. Am J Psychiatry. 2003; 160(1): 83-9. PubMed Abstract | Publisher Full Text

33. Hogan RE, Wang L, Bertrand ME, et al.: MRI-based high-dimensional hippocampal mapping in mesial temporal lobe epilepsy. Brain. 2004; 127(Pt 8): $1731-40$.

PubMed Abstract | Publisher Full Text

34. Csernansky JG, Schindler MK, Splinter NR, et al:: Abnormalities of thalamic volume and shape in schizophrenia. Am J Psychiatry. 2004; 161(5): 896-902. PubMed Abstract | Publisher Full Text

35. Wang L, Lee DY, Bailey E, et al:: Validity of large-deformation high dimensional brain mapping of the basal ganglia in adults with Tourette syndrome. Psychiatry Res. 2007; 154(2): 181-90. PubMed Abstract | Publisher Full Text | Free Full Text

36. Church JA, Fair DA, Dosenbach NU, et al.: Control networks in paediatric Tourette syndrome show immature and anomalous patterns of functional connectivity. Brain. 2009; 132(Pt 1): 225-238.

PubMed Abstract | Publisher Full Text | Free Full Text

37. Mugler JP, Brookeman JR: Three-dimensional magnetization-prepared rapid gradient-echo imaging (3D MP RAGE). Magn Reson Med. 1990; 15(1): 152-7. PubMed Abstract | Publisher Full Text

38. Haller JW, Banerjee A, Christensen GE, et al.: Three-dimensional hippocampal MR morphometry with high-dimensional transformation of a neuroanatomic atlas. Radiology. 1997; 202(2): 504-10.

PubMed Abstract

39. Desikan RS, Ségonne F, Fischl B, et al:: An automated labeling system for subdividing the human cerebral cortex on MRI scans into gyral based regions of interest. Neuroimage. 2006; 31(3): 968-80.

PubMed Abstract | Publisher Full Tex

40. Csernansky JG, Wang L, Joshi SC, et al.: Computational anatomy and neuropsychiatric disease: probabilistic assessment of variation and statistical inference of group difference, hemispheric asymmetry, and time-dependent change. Neuroimage. 2004; 23(Suppl 1): S56-68.

PubMed Abstract | Publisher Full Text

41. Ludolph AG, Juengling FD, Libal G, et al.: Grey-matter abnormalities in boys with Tourette syndrome: magnetic resonance imaging study using optimised voxelbased morphometry. Br J Psychiatry. 2006; 188: 484-485.

PubMed Abstract | Publisher Full Text

42. Roessner V, Overlack S, Schmidt-Samoa C, et al:: Increased putamen and callosal motor subregion in treatment-naïve boys with Tourette syndrome indicates changes in the bihemispheric motor network. J Child Psychol Psychiatry. 2011; 52(3): 306-14.

PubMed Abstract | Publisher Full Text

43. Peterson $\mathrm{BS}$, Thomas $\mathrm{P}, \mathrm{Kane} \mathrm{MJ}$, et al:: Basal ganglia volumes in patients with Gilles de la Tourette syndrome. Arch Gen Psychiatry. 2003; 60(4): 415-424. PubMed Abstract | Publisher Full Text

44. Moriarty J, Varma AR, Stevens J, et al:: A volumetric MRI study of Gilles de la Tourette's syndrome. Neurology. 1997; 49(2): 410-415. PubMed Abstract | Publisher Full Text

45. Zimmerman AM, Abrams MT, Giuliano JD, et al:: Subcortical volumes in girls with tourette syndrome: support for a gender effect. Neurology. 2000; 54(12): 2224-9.

PubMed Abstract | Publisher Full Text

46. Roessner V, Overlack S, Baudewig J, et al:: No brain structure abnormalities in boys with Tourette's syndrome: a voxel-based morphometry study. Mov Disord. 2009; 24(16): 2398-403.

PubMed Abstract | Publisher Full Text

47. Peterson BS, Riddle MA, Cohen DJ, et al:: Reduced basal ganglia volumes in Tourette's syndrome using three-dimensional reconstruction techniques from magnetic resonance images. Neurology. 1993; 43(5): 941-949. PubMed Abstract | Publisher Full Text

48. Makki, Ml, Govindan RM, Wilson BJ, et al:: Altered fronto-striato-thalamic connectivity in children with Tourette syndrome assessed with diffusion tensor MRI and probabilistic fiber tracking. J Child Neurol. 2009; 24(6): 669-78.

PubMed Abstract | Publisher Full Text

49. Bloch MH, Leckman JF, Zhu H, et al.: Caudate volumes in childhood predict symptom severity in adults with Tourette syndrome. Neurology. 2005; 65(8): p. 1253-1258.

PubMed Abstract | Publisher Full Text | Free Full Text 


\section{Open Peer Review}

\section{Current Peer Review Status:}

\section{Version 1}

Reviewer Report 27 March 2014

https://doi.org/10.5256/f1000research.2550.r4285

(C) 2014 Müller-Vahl K. This is an open access peer review report distributed under the terms of the Creative Commons Attribution License, which permits unrestricted use, distribution, and reproduction in any medium, provided the original work is properly cited.

\section{Kirsten R Müller-Vahl}

Clinic of Psychiatry, Social psychiatry and Psychotherapy, Hannover Medical School, Hannover, Germany

In this study a relatively new and sophisticated method (using large-deformation, high dimensional brain mapping (HDBM-LD)) has been used to investigate for the first time structure geometry and volume of basal ganglia and thalamus in 13 children with Tourette syndrome (TS) compared to 16 healthy controls. Comparable to a prior study in adults with TS performed by the same group, no significant differences could be detected in volume, shape, or right/left asymmetry.

These findings are in contrast to several other studies suggesting a reduction of the volume of the caudate in both children and adults with TS. The major limitation of this study is the small sample size and the heterogeneity of the patients' group with respect to comorbidities and medication. In particular, medication with neuroleptic drugs might have influenced the results, since there is evidence that exposure to antipsychotic medication may cause basal ganglia enlargement. However, the study has also several strengths including the well experienced team of researchers, low age range and inclusion of children only, and excellent matching for age, sex, and handedness. I enjoyed reading the discussion, because results obtained in children were not mixed with those in adults.

The introduction would benefit from a more precise clinical description. For example: tics are no longer characterized as "stereotyped" movements, abdominal tension is an untypical example for a motor tic, and tics "may" be associated with other disorders such as Wilson's and Huntington's disease. The title and abstract are appropriate.

Although this study contributes to our understanding of the neurobiology of TS, comparable to most MRI studies in TS, it is limited by the small sample size and possible influences of medication and comorbidities. I would love to read the results of a follow-up study including a larger number of patients soon. 
Competing Interests: No competing interests were disclosed.

I confirm that I have read this submission and believe that I have an appropriate level of expertise to confirm that it is of an acceptable scientific standard.

Author Response 27 Mar 2014

Kevin J Black, Washington University School of Medicine, St. Louis, USA

We appreciate Dr. Müller-Vahl's thoughtful comments.

Competing Interests: No competing interests were disclosed.

Reviewer Report 24 January 2014

https://doi.org/10.5256/f1000research.2550.r3072

(C) 2014 Stern J. This is an open access peer review report distributed under the terms of the Creative Commons Attribution License, which permits unrestricted use, distribution, and reproduction in any medium, provided the original work is properly cited.

\section{Jeremy S. Stern}

Department of Neurology, St. George's Hospital and Medical School, London, UK

This study continues the quest for subtle structural abnormalities in striato-thalamo-cortical circuitry in Tourette syndrome. The technique is innovative and in this paper is negative for a relatively small number of children as it has been for a similar number of adults in the past. The technique has yielded positive results in certain other conditions. The current results are not consistent with some other larger studies of caudate volumes and the reasons for this are explored and are a common issue in this area. Given the small number of subjects with heterogeneity of comorbidities and medication history the negative result here cannot be definitive, as suggested in the discussion.

A common group of core authors in a small number of sites published the previous HDBM-LD work and so external replication, particularly of the so far positive results would be valuable. The methadology is described more fully in an earlier paper, but it is hard to confirm if it could be reproduced directly from this alone.

The title and abstract are appropriate.

Competing Interests: No competing interests were disclosed.

I confirm that I have read this submission and believe that I have an appropriate level of expertise to confirm that it is of an acceptable scientific standard. 
Author Response 11 Feb 2014

Kevin J Black, Washington University School of Medicine, St. Louis, USA

We greatly appreciate Prof. Stern's thoughtful comments about the relevance and limitations of this pilot study. The prior report (ref. 35 above) does describe the methods in detail.

Competing Interests: No competing interests were disclosed.

\section{Comments on this article}

\section{Version 1}

Author Response ( F1000Research Advisory Board Member) 13 Oct 2015

Kevin J Black, Washington University School of Medicine, St. Louis, USA

Garraux et al 2006 (doi:10.1002/ana.20765) can be added to the list of studies of brain structure in TS that did not find a significantly smaller caudate nucleus.

Competing Interests: No competing interests were disclosed.

The benefits of publishing with F1000Research:

- Your article is published within days, with no editorial bias

- You can publish traditional articles, null/negative results, case reports, data notes and more

- The peer review process is transparent and collaborative

- Your article is indexed in PubMed after passing peer review

- Dedicated customer support at every stage

For pre-submission enquiries, contact research@f1000.com 